\title{
Cataract Obscuring a Large Primary Choroidal Melanoma and Associated Exudative Retinal Detachment in the Left Eye: A Case Report
}

\author{
Efthalia Ntora ${ }^{\mathrm{a}, \mathrm{b}}$, Dimitrios Stefanos Nanas ${ }^{\mathrm{a}}$, Nikolaos Dragoumis ${ }^{\mathrm{a}}$, Stefanos Maloutas ${ }^{\mathrm{a}}$, \\ Panagiotis Oikonomidis ${ }^{\mathrm{a}}$
}

\begin{abstract}
Choroidal melanoma is the most common primary malignant intraocular tumor that rarely is left undiagnosed. We report a case of a lately detected choroidal melanoma associated with exudative retinal detachment and severe visual loss in the affected eye. The patient was referred to our clinic with visual acuity in the right eye $6 / 6$ while in the left eye was limited to light perception. Ophthalmic examination showed a large pigmented choroidal tumoral mass occupying most of the vitreous cavity and associated exudative retinal detachment. Ultrasonography confirmed a dome-shaped tumor with internal homogeneity, while anterior choroid, ciliary body and angle were found with no invasion. The fellow eye was examined thoroughly and no lesions were detected. Further clinical investigation for metastasis was negative. Negligence of the symptoms, gradual evolution of the tumor and late referral resulted in irreversible loss of vision. The patient had no other systemic pathology and was advised for enucleation in the left eye and follow-up. Choroidal melanoma is a serious malignancy that could threaten the patient's life and requires early detection and treatment. In large lesions enucleation is the treatment of choice.
\end{abstract}

Keywords: Choroidal melanoma; Exudative retinal detachment; Enucleation

\section{Introduction}

Choroidal melanoma is the most common primary intraocular malignancy in adults, accounts for $80 \%$ of all uveal melanomas and at present is rarely left undetected. We report a case of a large primary choroidal melanoma associated with exudative retinal detachment found in a patient who was referred

Manuscript accepted for publication December 02, 2014

${ }^{a}$ The 1st Department of Ophthalmology of Aristotle University of Thessaloniki, AHEPA University Hospital, St. Kyriakidi 1, 54636 Thessaloniki, Greece ${ }^{b}$ Corresponding Author: Efthalia Ntora, The 1st Department of Ophthalmology, Aristotle University of Thessaloniki, AHEPA Hospital, St. Kyriakidi 1, 54636 Thessaloniki, Greece. Email: thaliadora@gmail.com

doi: http://dx.doi.org/10.14740/jmc2004w with mature cataract and severe visual loss in his left eye. Patient's negligence of the symptoms deprived him of an early diagnosis, use of more conservative therapeutic methods and the possibility to save vision. Enucleation was performed and absence of metastatic disease was confirmed surprisingly for such a large melanoma because of lead time bias.

\section{Case Report}

A 72-year-old male patient presented to our clinic with a progressive impairment in the vision of the left eye that had been evolving for 3 years. The patient described blurred vision without light flashes. No relevant findings were noted in his personal or familial medical history and no consumption of medication was declared.

Ophthalmic examination showed that the best corrected visual acuity in the right eye was $6 / 6 \mathrm{cc}(+3.00 \mathrm{sph},-1.00 \mathrm{cyl} \times$ $85^{\circ}$ ), while in the left eye was limited to light perception. The intraocular pressure was found $15 / 14 \mathrm{~mm} \mathrm{Hg}$ with applanation tonometry respectively. Slit lamp examination of the anterior segment revealed immature corticonuclear cataract in his right eye and dense nuclear and subcapsular cataract in his left eye. Gonioscopy excluded any sign of angle invasion respectively. Dilated fundoscopy revealed unremarkable findings in the right eye while an incidental pigmented choroidal mass with an extended exudative retinal detachment was noticed in the left eye.

The patient underwent A-B ultrasonography in both eyes which confirmed the presence of a tumor in the left eye. Specific criteria of standardized echography $[1,2]$ were used to determine its characteristics. The solid consistency tumor was dome-shaped with lobulated surface contour in the temporal periphery of the fundus arising from the choroid. The internal reflectivity was low to medium with regular structure. Internal blood flow was not indicated. The measurement of the tumor was $10 \mathrm{~mm}$ thickness and $17.2 \mathrm{~mm}$ basal diameter and was classified as a large tumor. Other findings included sound attenuation with extended exudative retinal detachment. No extrascleral tumor extension was observed (Fig. 1).

Systemic investigations including blood and liver function tests, chest X-ray, liver ultrasonography, MRI and bone scan were scheduled immediately. The results from laboratory tests were as follows: AST: $12 \mathrm{U} / \mathrm{L}$ (N: 0 - 38), ALT: $24 \mathrm{U} / \mathrm{L}$ 


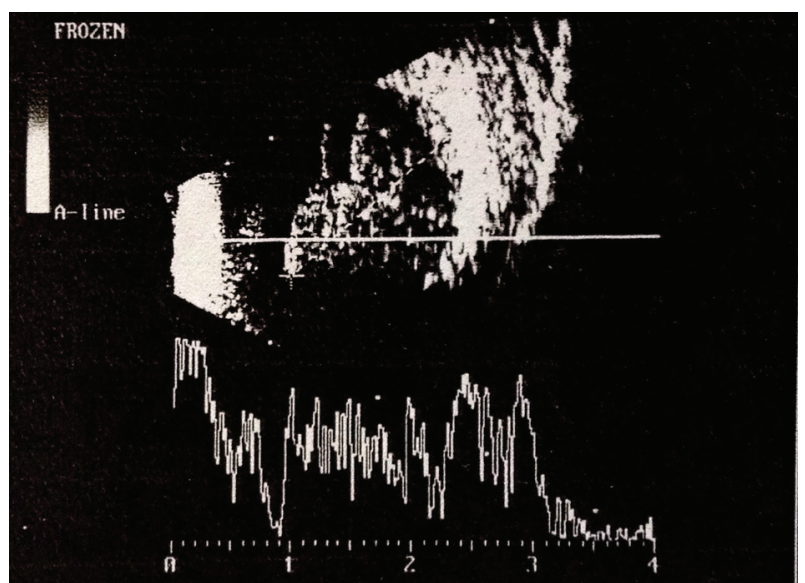

Figure 1. A-B ultrasound of the left eye: dome-shaped tumor $10 \times 17.2$ $\mathrm{mm}$, with low to medium reflectivity without extrascleral extension. An exudative retinal detachment is present.

(N: 0 - 40), $\gamma$-GT: $16 \mathrm{U} / \mathrm{L}(\mathrm{N}: 8$ - 61), ALP: $62 \mathrm{U} / \mathrm{L}(\mathrm{N}: 40-$ 129), LDH: $153 \mathrm{U} / \mathrm{L}(\mathrm{N}: 135$ - 225), CEA: $3.44 \mathrm{ng} / \mathrm{mL}(\mathrm{N}:<$ 3.8), PSA: $1.52 \mathrm{ng} / \mathrm{mL}(\mathrm{N}:<4.4)$, WBC: $6,870 / \mu \mathrm{L}(\mathrm{N}: 3,800$ 10,500), RBC: $4.84 \times 10^{6} / \mu \mathrm{L}\left(\mathrm{N}: 4.20 \times 10^{6}-6.30 \times 10^{6}\right), \mathrm{Hb}$ : $15.3 \mathrm{~g} / \mathrm{dL}(\mathrm{N}: 14-18), \mathrm{Ht}: 44.7 \%(\mathrm{~N}: 40-52 \%)$, platelets: 170 $\times 10^{6} / \mu \mathrm{L}\left(150 \times 10^{6}-450 \times 10^{6}\right), \mathrm{PT}: 11.30 \mathrm{~s}(\mathrm{~N}: 10-13.5)$, APTT: 28.9 s (N: 25 - 35), INR: 0.92 (N: 0.85 - 1.15).

The chest X-ray showed unremarkable findings without metastatic lesions.

The abdominal ultrasonography revealed a diffuse increase in hepatic echogenicity produced by fatty infiltration without evidence of metastasis. No other pathological findings were detected.

The orbit MRI confirmed a $9.7 \mathrm{~mm}$ thickness and $16 \mathrm{~mm}$ basal diameter choroidal mass in the left eye, homogenous and hyperintense in T1-weighted image and hypointense in T2-

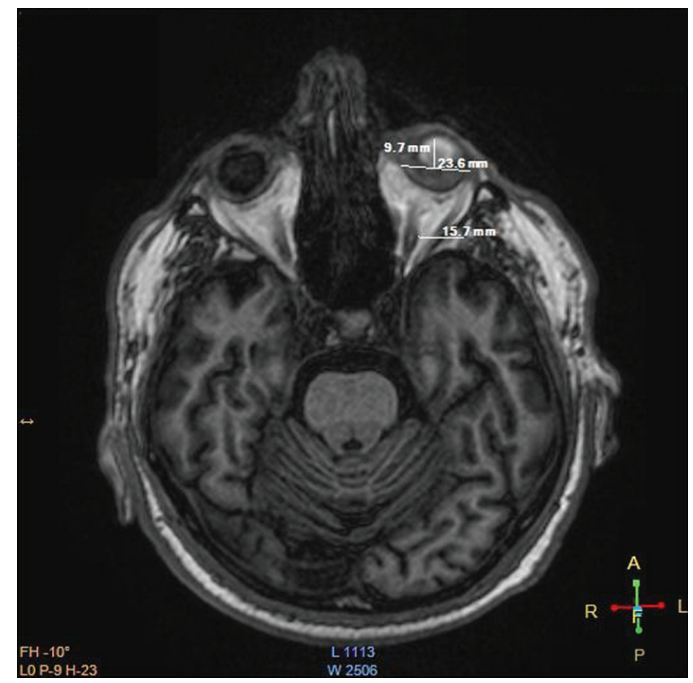

Figure 2. Orbit MRI: axial T1-weighted MR image shows hyperintense mass $9.7 \times 15.7 \mathrm{~mm}$ in the inferior temporal periphery of the left eye, associated with an exudative retinal detachment $23.6 \mathrm{~mm}$. No extraocular extension is depicted.

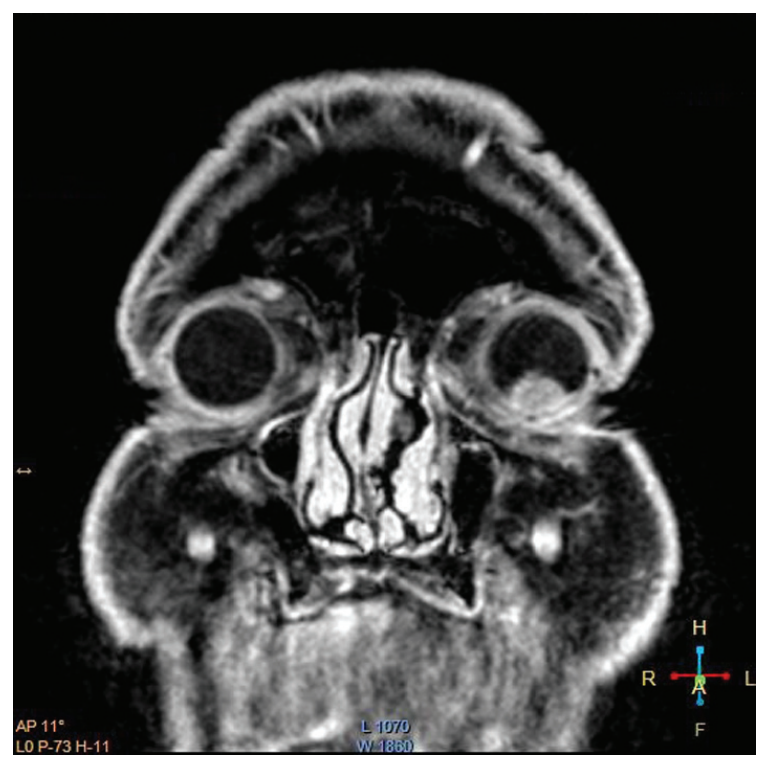

Figure 3. Orbit MRI: coronal section T1-weighted MR image shows the hyperintense mass in the left eye.

weighted image which is compatible to choroidal melanoma. Enhancement with gadolinium was medium and demonstrated the absence of extraocular extension as well as no signs of invasion in the anterior choroid and the ciliary body. An exudative retinal detachment extended up to $23.6 \mathrm{~mm}$ with presumable subretinal hemorrage was also diagnosed. No metastatic lesions were found in the brain MRI (Figs. 2-4).

The patient underwent a whole-body bone scan with Tc99m-methylene diphosphonate (MDP) gamma camera that excluded any secondary metastatic bone lesions.

Enucleation of the left eye was performed. Pathologic evaluation confirmed the choroidal mass was a mixed cell

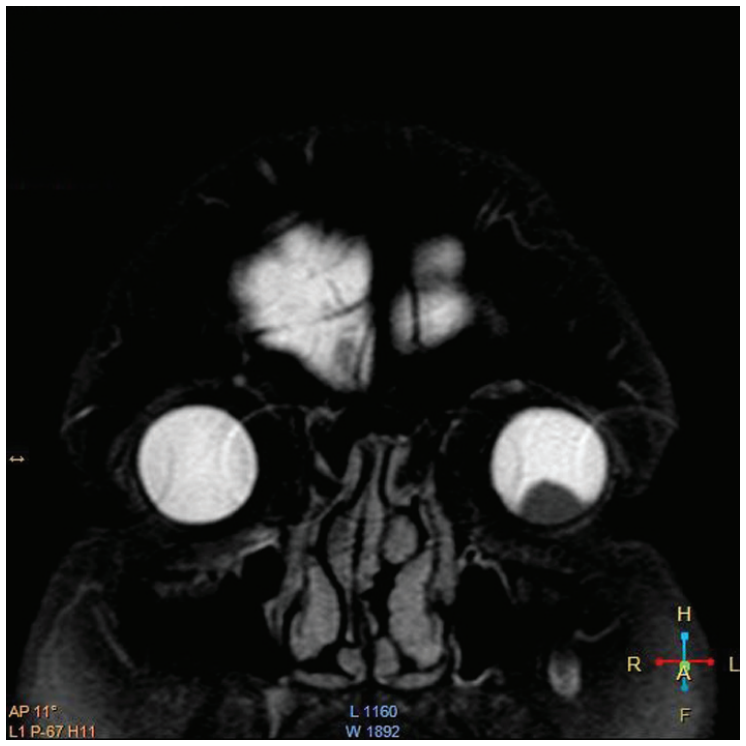

Figure 4. Orbit MRI: coronal section T2-weighted image shows the hypointense mass in the left eye. 
type malignant melanoma consisting of spindle and epitheliod cells, $12 \mathrm{~mm}$ thickness and $20 \mathrm{~mm}$ basal diameter. The tumor cells showed slight pigmentation with mild mitotic activity and were found to approach the ciliary body and invade the angle of the anterior chamber. Focal necrosis of tumor cells within the sclera was also detected (TNM classification as pT4b). The optic nerve margins were intact. The tumor was associated with an extended serous retinal detachment.

The patient was strongly advised to submit for regular systemic follow-up examinations by both an ophthalmologist as well as a medical oncologist. Particular evaluation of the liver, lungs, skin and brain was scheduled as this malignancy has a well-documented capacity to metastasize hematogenously to these sites. An ocular prosthesis can be applicable after a few months to restore the cosmetic result.

\section{Discussion}

The mean age-adjusted incidence of uveal melanoma in the United States was 5.1 per million while in Europe fluctuates from a minimum of 2 per million in registries of Spain and southern Italy, up to 8 per million in Norway and Denmark $[3,4]$. It arises from melanocytes within the choroid and has a slight predisposition for males. It is often diagnosed in the sixth decade of life [5]. Small lesions (thickness $<2 \mathrm{~mm}$, basal diameter $<8 \mathrm{~mm}$ ) are often asymptomatic, unless the patient's central vision is affected. Medium sized (thickness $2.5-8 \mathrm{~mm}$, basal diameter $8-16 \mathrm{~mm}$ ) and large lesions (thickness $>8 \mathrm{~mm}$, basal diameter $>16 \mathrm{~mm}$ ) are more likely to present with decreased visual acuity, metamorhopsia, photopsia, floaters and visual field loss. Other signs such as vitreous and subretinal hemorrhage, secondary glaucoma, intraocular inflammation, cataract and associated exudative retinal detachment may occur. Modern diagnostic tools, including gene expression profiling $[6,7]$, intravitreal biopsy, optical coherence tomography and magnetic tomography of the globe and orbital tissues, have led to significant advances in the ability to early diagnose such lesions. According to literature, the clinical diagnosis of choroidal melanoma has an accuracy of more than $99 \%$ [8]. Biopsy of classic medium size and larger tumors is not generally regarded as necessary for diagnosis.

The patient had no preexisting melanocytic nevi or other predisposed factors to choroidal melanoma [9]. Negligence of the symptoms deprived him of a routine eye examination and an early diagnosis.

The great majority of patients, approximately $98 \%$, who have been diagnosed with a choroidal melanoma have no detectable extraocular or metastatic disease at the time of detection of the tumor [10]. Those who have concurrent clinically detectable metastatic disease usually have a very large intraocular tumor and frequently have nodular extrascleral tumor extension. Important prognostic survival factors from metastatic melanoma include the size of the tumor (the larger the tumor, the worse the prognosis), the location of the tumor (tumors within the ciliary body are associated with a poorer prognosis than those confined to the choroid), the age of the patient at the time of diagnosis (the older the patient, the worse the short-term survival prognosis) and extrascleral tumor extension. Ten-year survival rates for uveal melanomas have been published as $81.2 \%$ for small melanomas, $60.0 \%$ for medium melanomas, and $34.8 \%$ for large melanomas $[11,12]$.

Concerning the treatment, in our case enucleation of the left eye was proposed as the treatment of choice based on the size of the tumor and the irreversible loss of vision. This method is most strongly indicated in large tumors that cause the eye to be blind and painful, tumors that surround or invade the optic nerve and when there is no possibility to salvage the eye by irradiation. Furthermore, results from the literature survival studies indicate that pre-enucleation radiation therapy does not improve survival appreciably compared with enucleation alone [13].

As long as tumor cells have not metastasized via the bloodstream to distant organs before or at the time of enucleation, this treatment should be curative; however, hematogenous dissemination of tumor cells appears to occur regularly in patients with uveal melanomas, and microscopic metastasis cannot be detected reliably by currently available methods. Consequently, failure of systemic investigation to show metastatic disease before enucleation does not guarantee that metastatic tumors will not emerge in the future. Approximately half of all patients who have a choroidal or ciliary body melanoma treated by enucleation eventually die of metastatic melanoma [14]. Cosmetic results with an ocular prosthesis are quite satisfactory. Most patients adapt well to their monocular status within a few months.

\section{Conflict of Interest}

Authors declare no conflict of interest.

\section{References}

1. Byrne SF, Green RL. Ultrasound of the Eye and Orbit. Second edition. Mosby. Chap 5. 2002:115-142.

2. Maloutas SG. Diagnostic Eye Sonography. First edition. University Studio Press. Chap 6. 1999:54.

3. Singh AD, Turell ME, Topham AK. Uveal melanoma: trends in incidence, treatment, and survival. Ophthalmology. 2011;118(9):1881-1885.

4. Virgili G, Gatta G, Ciccolallo L, Capocaccia R, Biggeri A, Crocetti E, Lutz JM, et al. Incidence of uveal melanoma in Europe. Ophthalmology. 2007;114(12):2309-2315.

5. Egan KM, Seddon JM, Glynn RJ, Gragoudas ES, Albert DM. Epidemiologic aspects of uveal melanoma. Surv Ophthalmol. 1988;32(4):239-251.

6. van den Bosch T, Kilic E, Paridaens D, de Klein A. Genetics of uveal melanoma and cutaneous melanoma: two of a kind? Dermatol Res Pract. 2010;2010:360136.

7. Kilic E, Naus NC, van Gils W, Klaver CC, van Til ME, Verbiest MM, Stijnen T, et al. Concurrent loss of chromosome arm $1 \mathrm{p}$ and chromosome 3 predicts a decreased disease-free survival in uveal melanoma patients. Invest Ophthalmol Vis Sci. 2005;46(7):2253-2257. 
8. Accuracy of diagnosis of choroidal melanomas in the Collaborative Ocular Melanoma Study. COMS report no. 1. Arch Ophthalmol. 1990;108(9):1268-1273.

9. Shields CL. The hunt for the secrets of uveal melanoma. Clin Experiment Ophthalmol. 2008;36(3):277-280.

10. Rankin SJ, Johnston PB. Metastatic disease from untreated choroidal and ciliary body melanomas. Int Ophthalmol. 1991;15(2):75-78.

11. Hawkins BS. The Collaborative Ocular Melanoma Study (COMS) randomized trial of pre-enucleation radiation of large choroidal melanoma: IV. Ten-year mortality findings and prognostic factors. COMS report number 24. Am J Ophthalmol. 2004;138(6):936-951.

12. Diener-West M, Reynolds SM, Agugliaro DJ, Caldwell
R, Cumming K, Earle JD, Hawkins BS, et al. Development of metastatic disease after enrollment in the COMS trials for treatment of choroidal melanoma: Collaborative Ocular Melanoma Study Group Report No. 26. Arch Ophthalmol. 2005;123(12):1639-1643.

13. Melia M, Moy CS, Reynolds SM, Hayman JA, Murray TG, Hovland KR, Earle JD, et al. Quality of life after iodine 125 brachytherapy vs enucleation for choroidal melanoma: 5-year results from the Collaborative Ocular Melanoma Study: COMS QOLS Report No. 3. Arch Ophthalmol. 2006;124(2):226-238.

14. Gamel JW, McCurdy JB, McLean IW. A comparison of prognostic covariates for uveal melanoma. Invest Ophthalmol Vis Sci. 1992;33(6):1919-1922. 